\title{
Risk factors in clinically diagnosed presenile dementia of the Alzheimer type: a case-control study in northern England
}

\author{
D P Forster, A J Newens, D W K Kay, J A Edwardson
}

\begin{abstract}
Study objective - To investigate the relationship between presenile dementia of the Alzheimer type (PDAT) and family history, medical history, cigarette smoking, and exposure to aluminium.

Design - A case-control study in which 109 cases of clinically diagnosed PDAT and 109 controls matched for age and sex were compared for exposure to the risk factors. Odds ratios (ORs) were calculated using McNemar's test.
\end{abstract}

Setting - The northern health region of England.

Patients - Cases comprised those under 65 years diagnosed as having dementia by specialist services, who met clinical algorithm criteria for Alzheimer's disease (AD). Cases were confirmed at interview. Main results - Comparing cases with controls, (ORs) significantly greater than unity were obtained when there was a first degree relative with dementia (OR 2.5, $95 \%$ confidence interval $1.05,6.56)$, any relative with dementia (OR $2 \cdot 1,95 \%$ CI $1 \cdot 01,4 \cdot 55)$, and any relative aged less than 65 with dementia (OR 8.0, 95\% CI 1.07, 348). Exposure to moderate levels of cigarette smoking (cumulative) was not significant; nor was exposure to aluminium in drinking water, diet, and medicinal sources.

Conclusion - In this study of modest statistical power, a family history of dementia was confirmed as a risk factor in PDAT. No significant relationship between exposure to aluminium in water supplies, tea, and antacids was found. What is important, however, is the bioavailability of all dietary aluminium, determined by the concentrations of dissolved silicon in water: this requires further investigation.

\section{(f Epidemiol Community Health 1995;49:253-258)}

Alzheimer type dementia $(\mathrm{AD})$ is a heterogeneous disorder. Although the gene involved has not yet been determined, some early onset, inherited forms are associated with mutations ${ }^{1}$ in the gene for the amyloid precursor protein located on chromosome 21, while others show linkage ${ }^{2}$ to chromosome 14 . A high proportion of both familial and sporadic late onset $\mathrm{AD}$ is associated with the E-4 allele of apolipoprotein $\mathrm{E}$, the gene for which is carried on chromosome $19 .{ }^{3}$
In contrast to these advances in understanding the molecular genetics of $\mathrm{AD}$, much less is known about possible environmental risk factors. A number of casecontrol studies have been carried out and a collaborative re-analysis of the data from these found that a family history of dementia or Down's syndrome and, to a lesser extent, head trauma showed consistent, positive associations with the disease. ${ }^{45}$ Other individual studies have found significant relationships between $\mathrm{AD}$ and high maternal age, a family history of Parkinson's disease, and an inverse relationship to smoking. ${ }^{6-8} \mathrm{~A}$ number of epidemiological studies have suggested that there may be a geographical association between aluminium in drinking water and the prevalence of $A D .^{1011}$ Relatively few studies, however, have been restricted to presenile dementia of the Alzheimer type $(\text { PDAT })^{9}-$ most have included varying proportions of elderly cases.

In this case-control study, we investigated the association of family history of dementia and Parkinson's disease, maternal age, medical history, cigarette smoking, and exposure to aluminium from a number of sources with clinical PDAT, diagnosed before the age of 65 .

\section{Patients and methods}

Potential cases of PDAT were those patients referred to specialist hospital services in the Northern Regional Health Authority who had been diagnosed as having dementia before the age of 65 years during the period 1981-89. These potential cases were identified from hospital admissions to both general and psychiatric hospitals, brain computed tomography records, day hospitals, social services departments, private nursing homes, clinical psychologists, community psychiatric nurses, and general practitioners. $^{12}$

Hospital case notes were studied for each case, and patients were included if there was evidence of memory impairment lasting three months or more, accompanied by personality change or at least one other type of cognitive deficit, and where there was evidence that the symptoms had interfered with social functioning. ${ }^{13}$ A diagnostic algorithm, incorporating the NINCDS-ADRDA criteria for Alzheimer's disease and excluding cases of secondary dementia, for example when there was a Hachinski ischaemia score of 6 or above or a focal abnormality on computed tomogram, was applied to the case note information. ${ }^{1415}$ The method has been described fully elsewhere. ${ }^{12}$ 
Eligible cases for inclusion in the case-control study were therefore those patients alive at the time of follow up in 1990-92 who fulfilled DSM-III-R criteria for dementia, NINCDSADRDA criteria for Alzheimer's disease, and had not been considered by the diagnosing clinician or from other information to have dementia of some other type.

The mini-mental state examination (MMSE) was used to check cognitive impairment in each patient, and patients with a score of 25 or more out of 30 were excluded. ${ }^{16}$ Patients with a score of 17 to 24 on the MMSE were interviewed using the geriatric mental state (GMS) examination to exclude any possible non-organic psychiatric conditions, particularly depression. ${ }^{17}$ Further requirements for inclusion were that there was a suitable informant available for interview and permission was given by the responsible clinician to approach the patient and informant, ethical approval having been obtained from each health district in the region.

Each case was individually paired with a control matched for age and sex. Controls were randomly selected from the population of the northern health region by a two stage procedure. Firstly, for each case, a family health service authority (FHSA) was chosen randomly with a probability proportional to population size. The authority then supplied the names of five individuals of the same sex and age as the case. One of these was selected randomly and permission was sought from the GP to approach the potential control. Each potential control selected had an equal overall probability of selection. ${ }^{18}$ In situations in which the GP felt it was inappropriate to approach a control, the control refused, or a suitable informant was not available, a replacement control from the potential list of five was selected randomly. The possibility of dementia in the control was excluded by questions on orientation in time and space addressed to the control, and questions to the informant in respect of the control concerning memory difficulties, recently changed habits, and difficulty with usual household or work related tasks. ${ }^{19}$ In addition, the Blessed dementia scale was completed by the informant with respect to each control. ${ }^{20}$

All data concerning history of exposure in both cases and controls were obtained from informants. A questionnaire requesting information about the history of place of residence and occupations of cases and controls was mailed to informants in advance. A structured interview was then carried out with each informant concerning the exposure of cases and controls to possible risk factors for Alzheimer's disease. In cases, information on the course of the dementing disorder was obtained using questions from the history and aetiology schedule. ${ }^{17}$ The reference period for aetiological information in cases was the time before the onset of the first reported symptom of dementia. In the age matched controls, enquiry about exposure to risk factors was also restricted to the time before the onset of symptoms in the matched case. The structured interview mainly used questions previously validated in other studies, for example questions on smoking drawn from the general household survey. ${ }^{21}$ Questions not previously used were tested first in pilot studies.

The standardised interview schedule covered the family history of dementia, Parkinson's disease, and Down's syndrome; maternal age; disease and accident history; cigarette smoking; physical activity levels before onset; and exposure to aluminium, particularly in the diet (for example through sources such as tea drinking and in medication). All interviews with informants for both cases and controls were undertaken by a single observer (AJN) and all but one of these took place in the informant's home. Historical data (based on local authority districts in the mid to late 1980s) on aluminium levels in drinking water were available for the eastern part of the northern region and were supplemented by data for Cumbria provided by the local water company. ${ }^{10}$ These data on aluminium levels in water were related to the place of residence at which the individual had lived the longest in the 10 years before onset of the symptoms of dementia (and the equivalent point in time for controls). In analysis, the case-control pairing was maintained and odds ratios (ORs) were calculated using McNemar's test. The $95 \%$ confidence intervals $(95 \% \mathrm{CI})$ for ORs were calculated using the Confidence Interval Analysis programme. ${ }^{22}$

\section{Results}

A total of 211 cases of PDAT from the original identification and diagnostic checking processes were known to be alive. Thirty of these (13\%) had either moved out of the region or their current GP could not be traced. In 16 (8\%), the GP advised against interview; in 28 (13\%), no suitable information could be found; and in $3(1 \%)$, an alternative diagnosis to PDAT had been made by a consultant in the meantime. The informants for 134 cases were therefore approached but $15(11 \%)$ declined to participate and 119 interviews took place with cases and informants. As a result of the examination of the potential cases (MMSE and GMS/HAS), 10 did not fulfil our criteria for PDAT and were excluded. The 109 cases included were compared over a range of variables with eligible cases excluded because of death or other reasons. No significant differences were detected with regard to the estimated age of onset, sex, or residence. One control was selected randomly for each of the 109 cases. In controls, the first person approached consented in $58(53 \%)$, the second in $29(27 \%)$, and the third or subsequent person approached in $22(20 \%)$. No control was excluded on the grounds of dementia or other cognitive deficit.

Of the 109 cases, $48(44 \%)$ were men and $61(56 \%)$ were women. Altogether 104 (95\%) had a MMSE score of less than 17 (out of 30) and five had scores in the range 17 to 23 . In $7(6 \%)$ cases, there was current evidence of depression in addition to dementia. There was no case, however, in whom the depression could have caused the dementia symptoms. The mean (SD) age of onset of the disease was 
55.9 (3.9) years and the mean (SD) age at diagnosis by a specialist was $58.3(3.8)$ years. Table 1 shows the maternal age and the family history of dementia, Parkinson's disease, and Down's syndrome in cases of PDAT and matched controls.

Of the cases with PDAT, 26 (24\%) had at least one first degree relative with a history of dementia compared with 14 (13\%) of the controls (OR 2.5; 95\% CI 1.05, 6.56). When the analysis was carried out separately for those with a history of dementia in first degree relatives aged under 65 , then 65 and above, no significant differences were detected between cases and controls. Significantly more cases of PDAT than controls had any relative with a history of dementia at any age (OR $2 \cdot 1 ; 95 \%$ CI 1.01, 4.55) and dementia under the age of 65 (OR 8.0; 95\% CI 1.07, 348). An additional analysis was carried out for the 87 case-control pairs in which the case of PDAT had an onset of dementia symptoms before the age of 60 and results very similar to those reported in table 1 for all the presenile cases were obtained.

Exposure to certain diseases and injuries, which previous work had suggested might be linked to $\mathrm{AD}$, were investigated. In addition health related behaviour in the form of physical activity levels in the 10 years before symptom onset and cigarette smoking were documented. Cumulative cigarette smoking was measured by calculating the number of cigarette pack (20 cigarettes per pack) years smoked before symptom onset (table 2). In none of the vari- ables investigated were there significant differences between cases and controls. Since smoking might be related to the presence of atherosclerotic disease, the analysis was repeated using only the case-control pairs in whom neither had any evidence of atherosclerotic disease, including ischaemic heart disease, hypertension, and cerebrovascular disease. ${ }^{23}$ This additional analysis, based on 87 pairs, produced similar ORs to those reported in table 2 for all case-control pairs.

The analysis of putative risk factors reported in table 2 was carried out separately for the 26 pairs with a familial case (first degree relative with dementia) and the 83 pairs in which the case was non-familial. In each of these analyses, there was no substantial change to the nonsignificant ORs noted for all pairs in table 2.

Table 3 shows the results for dietary, medicinal, and drinking water sources of exposure to aluminium. When cases were compared with controls for tea drinking, an OR greater than 1 was obtained but this was non-significant. Similarly, the OR obtained for prolonged antacid use, defined as the use of an antacid for six months or more, was not significant (OR 1.6; $95 \%$ CI $0.77,3.51$ ).

A number of hypotheses was tested, based on arbitrary levels of aluminium in drinking water, related to a person's main place of residence in the 10 years before the onset of dementia (and the equivalent in controls) and to the birthplace. The latter analysis was restricted to the 80 case-control pairs in whom

Table 1 Maternal age and history of dementia, Parkinson's disease and Down's syndrome in presenile dementia of Alzheimer's type and matched controls

\begin{tabular}{|c|c|c|c|c|c|c|c|}
\hline Factor & ++ & -- & +- & -+ & $O R$ & $(95 \% C I)$ & $p$ value \\
\hline $\begin{array}{l}\text { Maternal age } 40 \mathrm{y} \text { or above } \\
\text { First degree relative with dementia } \\
\text { First degree relative }<65 \text { y with dementia } \\
\text { First degree relative }>65 \mathrm{y} \text { with dementia } \\
\text { Any relative with dementia } \\
\text { Any relative }<65 \text { y with dementia } \\
\text { Any relative }>65 \text { y with dementia } \\
\text { First degree relative with Parkinson's } \\
\text { disease }\end{array}$ & $\begin{array}{l}0 \\
6 \\
0 \\
5 \\
6 \\
0 \\
5\end{array}$ & $\begin{array}{r}96 \\
75 \\
102 \\
79 \\
66 \\
100 \\
70 \\
105\end{array}$ & $\begin{array}{r}4 \\
20 \\
6 \\
17 \\
25 \\
8 \\
22 \\
2\end{array}$ & $\begin{array}{r}9 \\
8 \\
1 \\
8 \\
12 \\
1 \\
12 \\
2\end{array}$ & $\begin{array}{l}0 \cdot 4 \\
2 \cdot 5 \\
6 \cdot 0 \\
2 \cdot 1 \\
2 \cdot 1 \\
8 \cdot 0 \\
1 \cdot 8 \\
1 \cdot 0\end{array}$ & $\begin{array}{l}(0 \cdot 1,1.59) \\
(1 \cdot 05,6 \cdot 56) \\
(0 \cdot 72,277) \\
(0 \cdot 87,5 \cdot 69) \\
(1.01,4.55) \\
(1 \cdot 07,348) \\
(0 \cdot 87,4 \cdot 06) \\
(0.07,13.8)\end{array}$ & $\begin{array}{l}\text { NS } \\
0 \cdot 037 \\
\text { NS } \\
\text { NS } \\
0 \cdot 048 \\
0 \cdot 039 \\
\text { NS } \\
\text { NS }\end{array}$ \\
\hline $\begin{array}{l}\text { First degree relative with Down's } \\
\text { syndrome }\end{array}$ & 0 & 107 & 1 & 1 & $1 \cdot 0$ & $(0.01,78 \cdot 1)$ & NS \\
\hline
\end{tabular}

OR = odds ratio $; 95 \% \mathrm{CI}=95 \%$ confidence interval

++ Number of matched pairs in which both the case and control are positive for the factor; -- number of matched pairs in which both the case and control are negative for the factor; +- number of matched pairs in which the case is positive for the factor and the control is negative; - + number of matched pairs in which the case is negative for the factor and the control is positive. Table 2 Medical history and health related behaviour in cases of presenile dementia of Alzheimer's type and matched
controls

\begin{tabular}{|c|c|c|c|c|c|c|c|}
\hline Factor & ++ & -- & +- & -+ & $O R$ & $(95 \%$ CI) & $p$ value \\
\hline $\begin{array}{l}\text { Thyroid disease } \\
\text { Conditions involving atherosclerosis } \\
\text { Any head injury } \\
\text { Adult head injury } \\
\text { Childhood head injury } \\
\text { Meningitis } \\
\text { Physical underactivity } \\
\text { Cigarette smoking: }\end{array}$ & $\begin{array}{l}0 \\
1 \\
7 \\
4 \\
1 \\
0 \\
0\end{array}$ & $\begin{array}{r}94 \\
87 \\
69 \\
75 \\
98 \\
104 \\
104\end{array}$ & $\begin{array}{r}7 \\
7 \\
18 \\
18 \\
4 \\
2 \\
4 \\
4\end{array}$ & $\begin{array}{r}8 \\
14 \\
15 \\
12 \\
6 \\
3 \\
1\end{array}$ & $\begin{array}{l}0.9 \\
0.5 \\
1.2 \\
1.5 \\
0.7 \\
0.7 \\
4.0\end{array}$ & $\begin{array}{l}(0.27,2.76) \\
(0.17,1.32) \\
(0.57,2.56) \\
(0.68,3.41) \\
(0.14,2.81) \\
(0.05,5.82) \\
(0.39,1.96)\end{array}$ & $\begin{array}{l}\text { NS } \\
\text { NS } \\
\text { NS } \\
\text { NS } \\
\text { NS } \\
\text { NS } \\
\text { NS }\end{array}$ \\
\hline $\begin{array}{l}\text { Ever smoked } \\
11 \text { or more pack years } \\
30 \text { or more pack years }\end{array}$ & $\begin{array}{r}46 \\
26 \\
6\end{array}$ & $\begin{array}{l}12 \\
23 \\
60\end{array}$ & $\begin{array}{l}20 \\
26 \\
23\end{array}$ & $\begin{array}{l}31 \\
34 \\
20\end{array}$ & $\begin{array}{l}0 \cdot 6 \\
0 \cdot 8 \\
1 \cdot 1\end{array}$ & $\begin{array}{l}(0 \cdot 35,1 \cdot 17) \\
(0 \cdot 44,1 \cdot 31) \\
(0 \cdot 60,2 \cdot 21)\end{array}$ & $\begin{array}{l}\text { NS } \\
\text { NS } \\
\text { NS }\end{array}$ \\
\hline
\end{tabular}

OR=odds ratio $95 \% \mathrm{CI}=95 \%$ confidence interval.

++ Number of matched pairs in which both the case and control are positive for the factor; - - number of matched pairs in which both the case and control are negative for the factor; +- number of matched pairs in which the case is positive for the factor and the control is negative; -+ number of matched pairs in which the case is negative for the factor and the control is positive. 
Table 3 Dietary, medicinal, and drinking water sources of aluminium in cases of presenile dementia of Alzheimer's type and matched controls

\begin{tabular}{|c|c|c|c|c|c|c|c|}
\hline Source of aluminium & ++ & -- & +- & -+ & $O R$ & $95 \% C I$ & $p$ value \\
\hline $\begin{array}{l}\text { Drank }>4 \text { cups } / \mathrm{d} \text { of tea } \\
\text { Prolonged antacid use } \\
\text { Mean aluminium concentration in } \\
\text { drinking water at place of residence } 10 y \\
\text { before dementia onset }(\mu \mathrm{g} / \mathrm{l}) \text { : }\end{array}$ & $\begin{array}{r}29 \\
1\end{array}$ & $\begin{array}{l}26 \\
74\end{array}$ & $\begin{array}{l}32 \\
21\end{array}$ & $\begin{array}{l}22 \\
13\end{array}$ & $\begin{array}{l}1 \cdot 4 \\
1 \cdot 6\end{array}$ & $\begin{array}{l}(0 \cdot 81,2 \cdot 63) \\
(0 \cdot 77,3 \cdot 51)\end{array}$ & $\begin{array}{l}\text { NS } \\
\text { NS }\end{array}$ \\
\hline 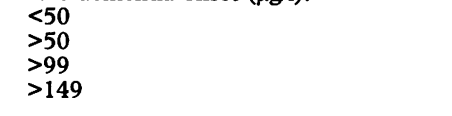 & $\begin{array}{r}14 \\
50 \\
43 \\
2\end{array}$ & $\begin{array}{l}50 \\
14 \\
17 \\
83\end{array}$ & $\begin{array}{l}25 \\
20 \\
22 \\
12\end{array}$ & $\begin{array}{l}20 \\
25 \\
27 \\
12\end{array}$ & $\begin{array}{l}1 \cdot 2 \\
0 \cdot 8 \\
0 \cdot 8 \\
1 \cdot 0\end{array}$ & $\begin{array}{l}(0.67,2.37) \\
(0.42,1.50) \\
(0.44,1.49) \\
(0.41,2.43)\end{array}$ & $\begin{array}{l}\text { NS } \\
\text { NS } \\
\text { NS } \\
\text { NS }\end{array}$ \\
\hline $\begin{array}{l}\text { Mean concentration at birthplace (no of } p \\
<50 \\
>50 \\
>99 \\
>149\end{array}$ & $\begin{array}{l}\mathrm{rs}=80 \\
12 \\
34 \\
29 \\
1\end{array}$ & $\begin{array}{l}1): \\
34 \\
12 \\
14 \\
62\end{array}$ & $\begin{array}{r}19 \\
15 \\
17 \\
9\end{array}$ & $\begin{array}{r}15 \\
19 \\
20 \\
8\end{array}$ & $\begin{array}{l}1 \cdot 3 \\
0 \cdot 8 \\
0 \cdot 8 \\
1 \cdot 1\end{array}$ & $\begin{array}{l}(0.61,2 \cdot 68) \\
(0.37,1 \cdot 64) \\
(0.42,1 \cdot 71) \\
(0.38,3 \cdot 35)\end{array}$ & $\begin{array}{l}\text { NS } \\
\text { NS } \\
\text { NS } \\
\text { NS }\end{array}$ \\
\hline
\end{tabular}

$\mathrm{OR}=$ odds ratio; $95 \% \mathrm{CI}=95 \%$ confidence interval

++ Number of matched pairs in which both the case and control are positive for the factor; - - number of matched pairs in which both the case and control are negative for the factor; +- number of matched pairs in which the case is positive for the factor and the control is negative; -+ number of matched pairs in which the case is negative for the factor and the control is positive.

both had been born within the northern health region, for which we had data on aluminium concentrations. In testing these hypotheses, we were unable to reject the null hypothesis and no increasing gradient was detected in the ORs with increasing exposure to aluminium in water.

In addition, analysis of the risk factors reported in table 3 was carried out separately for the pairs with and without a familial case of AD. There were no important differences from the findings for all pairs reported in table 3 .

\section{Discussion}

In this case-control study, the effects of age (to an actual day of birth) and sex were controlled for and these variables were not therefore analysed. Age is of course an important risk factor. In earlier work on PDAT, we found that there was a gradient in the increase of age specific incidence rates from 0.9 per 100000 in the age group 45-49 years to 14.5 per 100000 in the age group $60-64$. Incidence rates in the age group 45-64 were higher, but not significantly so, in women than in men. ${ }^{12}$

It can be argued that younger cases of dementia are more likely to be investigated by specialist services, and that our methods of identification used these sources. It is also possible that if there is an environmental factor in the causation of $\mathrm{AD}$, with or without a genetic contribution, this factor may be more detectable when its effects are exhibited in younger patients. A disadvantage is the difficulty in assembling large numbers of young cases for study. Based on the 109 cases of PDAT and matched controls, a study of this size would have an approximate power of $80 \%$ to detect an odds ratio of 2.5 at the $5 \%$ level of significance, if the exposure of the controls to the putative risk factor were $30 \%$ (a typical value for smoking).

Based on clinical and interview information, we sought to establish a group of pure $A D$ cases in order to minimise misclassification and hence avoid weakening the power of the study to detect true associations. We had the advantage of a long follow up period which meant that cases with a temporary cognitive deficit could be excluded. Without neuropathology, however, it is difficult to be certain that patients with pure $\mathrm{AD}$ and not, for example, Lewy body disease have been identified. ${ }^{23}$ The use of the Hachinski score to exclude cases of vascular dementia may have led to the elimination of cases of mixed $A D$ and vascular pathology and, since smoking is associated with cardiovascular disease, may have reduced the recorded smoking rates in the cases of $\mathrm{AD} .^{7}$ The cases of PDAT have been diagnosed over a number of years and therefore comprised both prevalent and incident cases. The sample investigated could therefore contain an excess of those with longer survival who may respond differently to exposure to risk factors, ${ }^{24}$ although there is no reason to suspect this in this situation. Analysis following stratification of the case-control pairs by year of diagnosis did not identify any significant differences in risk factor exposure or odds ratios in different strata, suggesting that survival bias was unlikely to have occurred.

The case-control pairs were also analysed separately on the basis of whether the case was familial or non-familial. As with other risk factors, we did not find any important differences in the results in these separate groups compared with all the case-control pairs.

The selection of controls had to be neutral to environmental bias and therefore the method used could not identify them from the same general practice as the case. However, each control was randomly selected from the whole of the northern region and the compliance rate of $53 \%$ in the first control approached is similar to that obtained in a comparable study. ${ }^{7} \mathrm{Al}$ though the assessments used in controls, and through interviewing their informants, ruled out dementia at the time of interview, it cannot of course be guaranteed that they will never develop dementia in the future. Data on exposure to risk factors in both cases and controls were obtained in a similar manner from an informant who was a close relative..$^{25}$

This study confirms the previously found significant association of $\mathrm{AD}$ with a family history of dementia in first degree or all relatives and also dementia before the age of 65 in any 
relative. ${ }^{9}$ The dementia in relatives reported by informants, however, is not necessarily of the Alzheimer type. ORs above unity for late maternal age, a family history of Parkinson's disease, or Down's syndrome were not found. A study of this size would have only modest statistical power to detect such differences when exposure in controls (or the population) was low. The OR for head injury at any age was only slightly and non-significantly above unity. Although this factor has been found to be significant in a number of studies, the variation in the exposure rate between published studies suggests that its definition is not consistent. ${ }^{5}$ In two studies, physical underactivity earlier in life, particularly for early onset cases, has been reported. ${ }^{2627}$ The present study found a non-significant odds ratio of 4, but again in a situation of low exposure rates in controls.

All but one case-control study has shown an inverse association of $\mathrm{AD}$ with smoking. ${ }^{5}$ Most studies have indicated a decreased risk of $A D$ with an increase in smoking ${ }^{7}$ but one found the greatest risk reduction in those who smoked least. ${ }^{8}$ Inverse associations of smoking and $\mathrm{AD}$ in case-control studies might be a result of increased non-compliance of controls who smoke, or because older surviving smokers may be less susceptible to Alzheimer's through having more effective DNA repair mechanisms. ${ }^{28}$ The ORs for smoking obtained in this study, although not statistically significant, are consistent with an inverse relationship between $A D$ and smoking at moderate cumulative levels. The lowest ORs were obtained for lesser amounts of smoking but with no obvious doseresponse relationship.

The main source of exposure to aluminium is the diet but since this element is present in so many different chemical forms, the bulk concentration of aluminium in any particular dietary constituent provides no indication of its bioavailability. Aluminium is used widely in the flocculation treatment of water supplies and a number of epidemiological studies have indicated a geographical association between either the prevalence or incidence of $\mathrm{AD}$ and the concentration of aluminium in drinking water. ${ }^{101129}$ Aluminium in water accounts for a minute fraction of the total dietary intake of this element, however, and it has been proposed $^{30}$ that this geographical relationship is more likely to have been determined by the concentration of dissolved silicon in water, which has been shown to inhibit the gastrointestinal absorption of aluminium. ${ }^{31}$ Aluminium concentrations in brewed tea are some 10 to 100 times those in drinking water, ${ }^{32}$ although the presence of tannins and other organic constituents may significantly reduce the bioavailability of aluminium from this source. A major source of exposure is antacids containing aluminium, although two recent case-control studies have failed to find a significantly increased relative risk associated with their use. ${ }^{33} 34$

In this study, although ORs above unity were obtained for tea drinking and prolonged antacid use, these were not statistically significant, nor was there any significant risk associated with increased levels of aluminium in drinking water. There are problems in obtaining accurate data for each of these variables. For example, it was not always possible to be certain that a white mixture, reported as being taken for indigestion, was one containing aluminium. With respect to drinking water we only had data for mean levels of aluminium in water based on local authority areas for a time period in the mid to late 1980s. We were, however, able to apply these levels to the individuals in the study on the basis of their place of residence 10 years before the onset of the symptoms, and also to birthplace for the 80 case-control pairs who were born within the northern health region. For each of these analyses, the ORs were not significantly different from unity. Moreover, no striking dose-response relationships were evident. It should be noted, however, that aluminium levels in drinking water fluctuate and some of the concentrations used in this analysis might have related to a period following the onset of symptoms of $\mathrm{AD}$ rather than preceding it. This may have led to some misclassification which would obscure the detection of a true relationship between $\mathrm{AD}$ and high aluminium concentrations in water. When combinations of exposure to aluminium were analysed, for example being exposed to water containing $>99 \mu \mathrm{g} / \mathrm{l}$ or $>149 \mu \mathrm{g} / \mathrm{l}$ at the place of residence 10 years before dementia onset plus prolonged antacid use or high levels of tea drinking, no significantly raised ORs were detected. In these analyses, however, the prevalence of exposure of the controls to the risk factors is low and the power of the study reduced.

Our conclusion, based on this case-control study with modest statistical power, is that although neuropathological work suggests a role for aluminium in the onset of Alzheimer's type dementia, we have been unable to detect a large effect epidemiologically when examining exposure to aluminium. In an accompanying paper, we return to the issue of dissolved silicon in water, which influences the bioavailability of all sources of aluminium.

This study was supported by a grant from the Northern Regional Health Authority and a project grant from the Medical Research Council. We are very grateful for information provided by the National Health Service Central Register.

1 Chartier-Harlin MC, Crawford F, Houlden H et al. Earlyonset Alzheimer's disease caused by mutations at codon 717 of the $\beta$-amyloid precursor protein gene. Nature 1991 ; 353:844-6.

2 Schellenberg GD, Bird TD, Wijsman EM et al. Genetic linkage evidence for a familial Alzheimer's disease locus linkage evidence for a familial Alzheimer's diseas
on chromosome 14. Science 1992;258:668-71.

3 Corder EH, Saunders AM, Strittmayer WJ et al. Gene dose of Apolipoprotein E type 4 allele and the risk of Alzheimer's disease 1993;261:921

4 van Duijn CM, Stignen T, Hofman A. Risk factors for Alzheimer's disease: overview of the Eurodem collaborative re-analysis of case-control studies. Int $\mathcal{f} \mathrm{Ep}$ idemiol 1991;20(suppl. 2):4-11.

5 Clayton D. The Eurodem collaborative re-analysis of casecontrol studies of Alzheimer's disease: some methodological considerations. Int 7 Epidemiol 1991;20(supp. 2):62-4.

6 Cohen D, Eisdorfer C, Leverenz J. Alzheimer's disease and maternal age. F Am Geriatr Soc 1982;30:656-9.

7 van Duijn CM, Hofman A. Relation between nicotine intake and Alzheimer's disease. BMF 1991;302:1491-4.

8 Brenner DE, Kukull WA, van Belle G, Bowen JD, McCormick WC, Teri L, Larsen EB. Relationship between cimick $\mathrm{C}$, garette smoking and Alzheimer's disease in a populatio

9 Whalley LG, Carothers AD, Collyer S, De Mey R, Frack- 
iewicz, A. A study of familial factors in Alzheimer's disease. Br f Psychiatry 1982;140:249-56.

10 Martyn CN, Barker DJP, Osmond C, Harris EC, Edwardson JA, Lacy RF. Geographical relation between Alzheimer's disease and aluminium in drinking water. Lancet 1989; 59-62.

11 Neri LC, Hewitt D. Aluminium, Alzheimer's disease and drinking water. Lancet 1991;338:390.

12 Newens AJ, Forster DP, Kay DWK et al. Clinically diag nosed dementia of the Alzheimer type in the northern health region: ascertainment, prevalence, incidence and survival. Psychol Med 1993;23:631-44.

13 American Psychiatric Association. Diagnostic and statistical manual of mental disorders. 3rd ed rev. Washington DC American Psychiatric Association, 1987.

14 McKhann G, Drachman D, Folstein M, Katzman R, Price D, Stadlan EM. Clinical diagnosis of Alzheimer's disease: report of the NINCDS-ADRDA work group under the auspices of the Department of Health and Human Services Task Force on Alzheimer's disease. Neurology 1984;34: Task For

15 Hachinski VC, Iliff LD, Zilhka E et al. Cerebral blood flow in dementia. Arch Neurml 1975;32:632-7.

16 Folstein MF, Folstein S, McHugh P. Mini-mental state, a practical method for grading the cognitive state of patients for the clinician. $\mathcal{F}$ Psychiatr Res 1975;12:189-98.

17 Copeland JRM, Dewey ME. Neuropsychological diagnosis (GMS-HAS-AGECAT package). International Psychogeriatrics 1991;3(suppl.) 43-9.

18 Moser CA, Kalton G. Survey methods in social investigation. London: Heinemann, 1971.

19 Jorm AF, Korten AE. Assessment of cognitive decline in the elderly by informant interview. Br $\mathcal{F}$ Psychiatr 1988; 152:209-13.

20 Blessed G, Tomlinson BE, Roth $M$. The association between quantitative measures of dementia and of senile change in quantitative measures of dementia and of senile change in
the cerebral grey matter of elderly subjects. $B r f$ Psychiatry the cerebral grey matt

21 Office of Population Censuses and Surveys. The general household survey. London: HMSO, 1989.
22 Gardner MJ, Altman DG. Statistics with confidence. London: BMJ Group, 1989.

23 McKeith I, Fairburn A, Perry R, Thompson P, Perry E Neuroleptic sensitivity in patients with senile dementia of

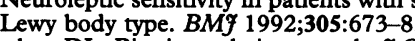

24 Sackett DL. Bias in analytic research. $\mathcal{F}$ Chron Dis 1979;32 51-63.

25 Korten AE, Jorm AF, Henderson AS, McCusker E, Creasey H. Control-informant agreement on exposure history in case-control studies of Alzheimer's disease. Int $₹$ Epidemio 1992;21:1121-31.

26 Broe GA, Henderson AS, Creasey $\mathrm{H}$ et al. A case-contro study of Alzheimer's disease in Australia. Neurology 1990 40:1698-1707.

27 Henderson AS, Jorm AF, Korten AE et al. Environmental risk factors for Alzheimer's disease: their relation to age of onset and to familial or sporadic types. Psychol Med 1992;22:429-36.

28 Rigos JE. Smoking and Alzheimer's disease: protective effect or differential survival bias. Lancet 1993;342:793-4.

29 Doll R. Review: Alzheimer's disease and environmental aluminium. Age Ageing 1993;22:138-53.

30 Birchall JD, Chappell JS. Aluminium, water chemistry and Alzheimer's disease. Lancet 1989;i:953.

31 Edwardson JA, Moore PB, Ferrier IN et al. Effects of silicon on gastrointestinal absorption of aluminium. Lancet 1993 349:211-12.

32 Gardner MJ, Gunn AM. Bioavailability of aluminium from food and drinking water. In: Lord Walton of Detchant ed. Alzheimer's disease and the environment. London: Royal Society of Medicine, 1991. Round Table Series no 26

33 Heyman A, Wilkinson WE, Stafford JL, Helms MJ, Sigmon AH, Weinberg T. Alzheimer's disease, a study of the epidemiological aspects. Ann Neurol 1984;15: of the

34 Graves AB, White E, Koepsell TD, Reiffler BV, van Bele $\mathrm{G}$, Larson EB. The association between aluminium containing products and Alzheimer's disease. $\mathcal{f}$ Clin Epidemiol taining products 